\title{
Hemodynamic Behavior in Third Molar Surgeries Using Lidocaine or Articaine
}

\author{
Comportamiento Hemodinámico en Cirugías de los \\ Terceros Molares Utilizando Lidocaína vs Articaina
}

\author{
Paulo Eduardo Melo Stella; Saulo Gabriel Moreira Falci; \\ Valéria Silveira Coelho \& Cássio Roberto Rocha dos Santos
}

STELLA, P. E. M.; FALCI, S. G. M.; COELHO, V. S. \& DOS SANTOS, C. R. R. Hemodynamic behavior in third molar surgeries using lidocaine or articaine. Int. J. Odontostomat., 12(1):76-85, 2018.

SUMMARY: The aim of this research was to assess the hemodynamic variations during the extraction of impacted lower third molars using lidocaine $2 \%$ or articaine $4 \%$, as local anesthetics. Fourteen patients with a mean age of 22.4 $(S D=3.25)$, were submitted to the bilateral extraction of lower third molars, with an interval of three to four weeks between the two extractions. Systolic blood pressure, diastolic blood pressure, mean arterial pressure, heart rate and oxygen saturation in the blood were assessed at seven specific time points: baseline; anesthetic puncture; two minutes after anesthesia; osteotomy; suture and five minutes after the procedure had been completed. The statistical analysis involved descriptive analysis, the Shapiro-Wilk test, the Mann-Whitney test, the t-test and the repeated measurements test. No significant differences were found for any of the hemodynamic behavior variables when comparing lidocaine $2 \%$ and articaine $4 \%$. Significant differences were found between the time points assessed within each group, particularly in relation to the variable heart rate. In the articaine group, systolic blood pressure exhibited a significant decrease five minutes after the procedure. There were no significant variations in hemodynamic behavior between the two different anesthetic groups (articaine $4 \%$ and lidocaine $2 \%$ ).

KEY WORDS: oral surgery, third molars, lidocaine, articaine, blood pressure.

\section{INTRODUCTION}

The extraction of impacted third molars is one of the most common procedures in oral and maxillofacial surgery (Kim et al., 2009). Abnormal patient behavior is often reported during these procedures, as a result of psychological factors, physical stress, painful stimuli and the action of anesthetic solutions (Abraham-Inpijn et al., 1988; Gortzak et al., 1992; Meiller et al., 1993; Tsuchihashi et al., 1996; Laragnoit et al., 2009).

Local anesthetics such as lidocaine and articaine are generally used in combination with a vasoconstrictor to delay the systemic absorption of the anesthetic, thereby prolonging its action and the intensity of the blockage (Silvestre et al., 2011). Vasoconstrictors can cause hemodynamic alterations during the surgical extraction of molars, similar to other factors, such as the patient's anxiety or stress levels
(Tolas et al., 1982). Although the safety of using a local anesthetic together with a vasoconstrictor has been confirmed in the literature (Neves et al., 2007; Elad et al., 2008), significant abnormalities have been recorded in the blood pressure and heart rate of patients submitted to the extraction of third molars (Vasconcellos et al., 2008; Sancho-Puchades et al., 2012).

Articaine has a number of pharmacological advantages over other local anesthetics, such as the replacement of the aromatic ring by a thiophene ring, which increases liposolubility and potency. The clinical advantages of articaine include the long duration of its anesthetic affect. It is only bettered by ultra-long anesthetics, such as bupivacaine, etidocaine and ropivacaine, which exhibit greater diffusion through the bone tissue (Oertel et al., 1994, 1997; Malamed et al., 2000). 
Lidocaine is the most commonly used anesthetic to control pain due to its greater pharmacokinetic characteristics and low toxicity, when compared with other ester anesthetics, which make it safe to use in clinical dentistry practice (Daubländer et al., 1997). Both lidocaine and articaine have the same maximum dose $(500 \mathrm{mg}$ ) for healthy adult patients (recommended dose: 6.6-7.0 mg/kg) (Malamed et al., 2000).

The aim of the present study was to determine if there are variations in the hemodynamic behavior of patients submitted to the extraction of lower third molars when using two different types of local anesthetics (lidocaine $2 \%$ and articaine $4 \%$ ).

\section{MATERIAL AND METHOD}

Study design. This randomized, double-blind, splitmouth clinical trial was approved by the Research Ethics Committee of the author's University under protocol number CAAE 43774115.9.0000.5108 (resolution 466/12). The research was conducted in accordance with the Helsinki Declaration of 1975 (revised in 2013) and also satisfied the Consolidated Standards of Reporting Trials Statement (CONSORT) (Schulz et al., 2010). All of the participants read and signed a free and informed statement of consent, confirming their acceptance to take part in the investigation.

Pilot study and sample calculation. A pilot study was conducted with four patients, who were submitted to bilateral surgery on impacted lower third molars. Based on this pilot study, the standard deviation value of the variable "systolic blood pressure" was obtained $(9.67 \mathrm{mmHg}$ ), which allowed the authors to calculate the sample. Considering a level of confidence of $95 \%$ and test power of $80 \%$, with the difference to be detected between the groups stipulated at $11 \mathrm{mmHg}$, the minimum sample requirement was 12 patients. Four further patients were added to compensate for possible losses during the research.

Sample selection, blinding and randomization. Sixteen healthy individuals, aged between 18-31 years and in possession of bilateral lower third molars, were selected to participate in the present study. In order to be included in this research, the lower third molars needed to be indicated for extraction by a dentist and either impacted or semi-impacted, with a similar surgical difficulty on both sides (Class II B), based on the Pell and Gregory classification (Pell \& Gregory, 1993), clinical examinations and radiographs. The following exclusion criteria were applied: patients with general health issues; patients that suffered from hypersensitivity to the drugs used in the research; as well as pregnant or lactating women.

Blinding was conducted so that the surgeon would not know which anesthetic would be used in each procedure. To do this, the anesthetic tubes were covered with two colored tapes, differentiating the two study groups. Only the assistant had access to the color codes.

Blinding was also conducted for the patient, who did not know the type of anesthetic used. During the initial examination (baseline), the patient was asked to select from four sealed envelopes. The first two referred to the type of treatment to be conducted (extraction of tooth 38 or extraction of tooth 48) and the last two referred to the type of anesthetic to be used (lidocaine $2 \%$ or articaine $4 \%$ ), both of which were used in conjunction with epinephrine 1:100.000. For each patient, the assistant opened the envelope and informed the surgeon which side would be operated and the code of the anesthetic to be used in the first operation. The second operation was conducted with the other type of anesthetic after 3-4 weeks.

Pre- and trans-operative assessment. Systolic blood pressure (SBP), diastolic blood pressure (DBP), mean arterial pressure (MAP), heart rate (HR) and peripheral oxygen saturation in the blood $(\mathrm{SaO} 2)$ were assessed at seven different time points during the surgical procedure: with the patient at rest at baseline (T0); during the injection of the local anesthetic (T1); two minutes after the injection of the anesthetic (T2); incision and displacement of the soft tissue (T3); osteotomy, odontosection and luxation (T4); cleaning the cavity and suture (T5) and five minutes after the end of the procedure (T6). All of these assessments were performed using a Modular Vital Signs Monitor with an internal video (DX 2023, Dixtal Biomédica Ind. e Com. LTDA, São Paulo-SP).

Surgical procedure. Each patient was submitted to two surgical extractions, which were separated by a period of three to four weeks. The surgery was performed by the same surgeon, who was a specialist in Oral and Maxillofacial Surgery. In the clinical examination (prior to surgery), the patients were monitored for vital signs (SBP, DBP, MAP, HR and $\mathrm{SaO} 2)$. Extraoral antisepsis was conducted using an 
alcohol solution with povidone iodine $10 \%$ (PVP-I). Anesthesia of the lower alveolar nerve was performed with lidocaine $2 \%$ (plus 1:100.000 of epinephrine) or articaine $4 \%$ (plus $1: 100.000$ of epinephrine), using a volume of $5.4 \mathrm{ml}$ (3 tubes). Care was taken to avoid injecting the anesthetic intravascularly. The methods to be used were standardized for all of the surgical procedures. Firstly, an incision was made in the alveolar ridge (from distal to medial on the mandibular ramus), ending at the distolingual section of the second molar. This was followed by an intrasulcular incision from the second molar to the region of the interdental papilla, between the first and second molars.

The mucoperiosteal flap was lifted and osteotomy was conducted. The tooth was sectioned and removed using Seldin elevators, followed by careful curettage and bone regularization. The surgical cavity was cleaned by means of abundant irrigation with saline. The flap was sutured through isolated spots using silk thread 4.0. Five minutes after the end of the suture, the vital signs monitor was removed from the patient. The total duration of the procedure, including all of the monitoring, was approximately 45 minutes.
After all surgical procedures, the patients received instructions related to local hemostasis, nourishment, cleaning the operated section of the mouth, restrictions on physical effort and other routine post-operative recommendations. They were instructed to take one $750 \mathrm{mg}$ paracetamol pill every six hours (only if they felt pain) and one $600 \mathrm{mg}$ ibuprofen pill every eight hours for five days, was approximately 45 minutes, in both procedures of each patient.

Statistical analysis. The data analysis was conducted using the Statistical Package for Social Sciences (SPSS for Windows, version 20.0, SPSS Inc. Chicago, IL, USA) and included descriptive analysis and association tests to compare the anesthetics (lidocaine and articaine). The ShapiroWilk test was used to assess the occurrence (or not) of a normal distribution. Parametric or non-parametric tests were applied, when indicated. The MannWhitney test was used to compare the hemodynamic assessments for the measurements of mean arterial pressure and oxygen saturation in the blood at all of the time points in both groups. The t-test for independent samples was used for the variables SBP,

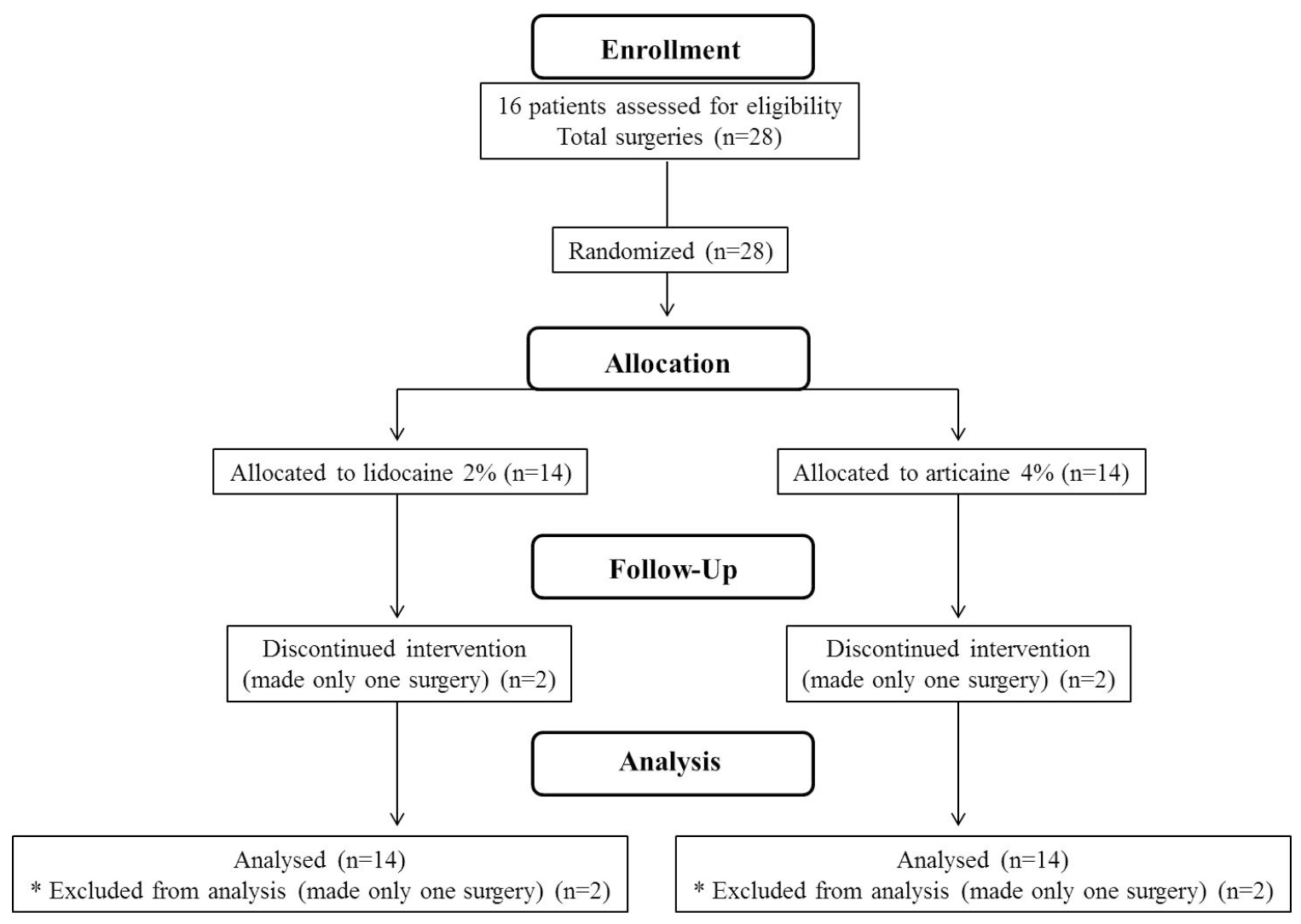

Fig. 1 CONSORT Flow diagram. 
DBP and HR. The repeated measurements test was used to confirm the variations in hemodynamic behavior between the time points assessed in each group.

\section{RESULTS}

Sixteen patients began the clinical trial, although two of them did not complete all stages since they only underwent one surgical procedure (Fig. 1). One patient could not have the second surgical procedure due to scheduling problems and the other suffered a postoperative infection after the first procedure and refused to participate further in the research. Therefore, 14 patients (two men and 12 women), with a mean age of 22.4 years $(S D=3.25)$, participated in all stages of this research.

No significant differences were found between the mean values for DBP, SBP, MAP, HR and $\mathrm{SaO} 2$, when comparing the two anesthetics at all of the time points assessed (Figs. 2-6).

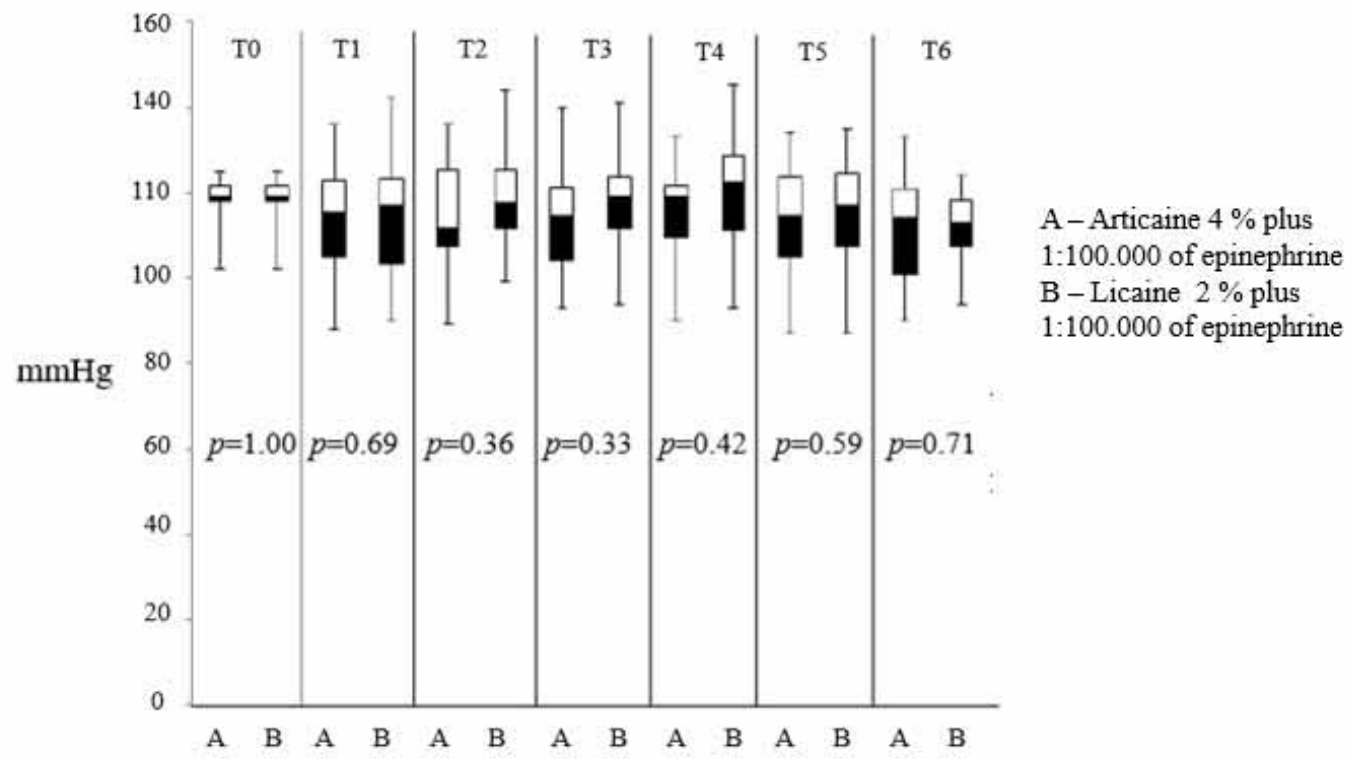

Fig. 2. Systolic blood pressure difference in every moment during surgery, comparing articaine and lidocaine; $p<0.05$ : Statistically significant difference.

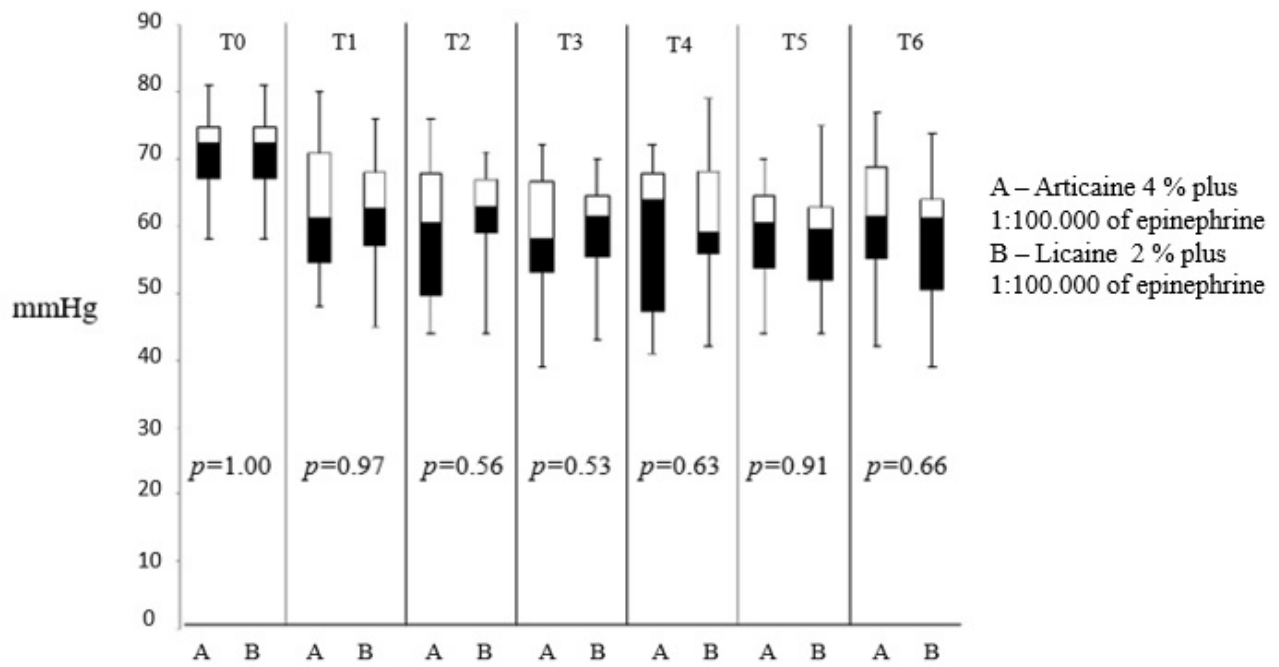

Fig. 3. Diastolic blood pressure difference in every moment during surgery, comparing articaine and lidocaine; $p<0.05$ : Statistically significant difference. 
STELLA, P. E. M.; FALCI, S. G. M.; COELHO, V. S. \& DOS SANTOS, C. R. R. Hemodynamic behavior in third molar surgeries using lidocaine or articaine. Int. J. Odontostomat., 12(1):76-85, 2018.

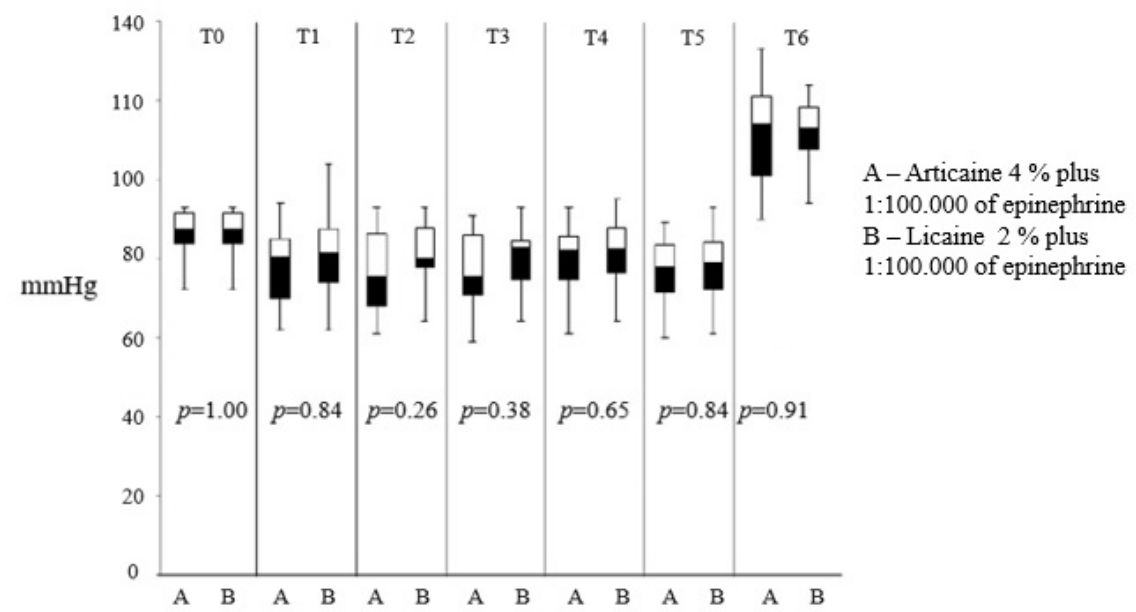

Fig. 4. Mean arterial pressure difference in every moment during surgery, comparing articaine and lidocaine; $p<0.05$ : Statistically significant difference.

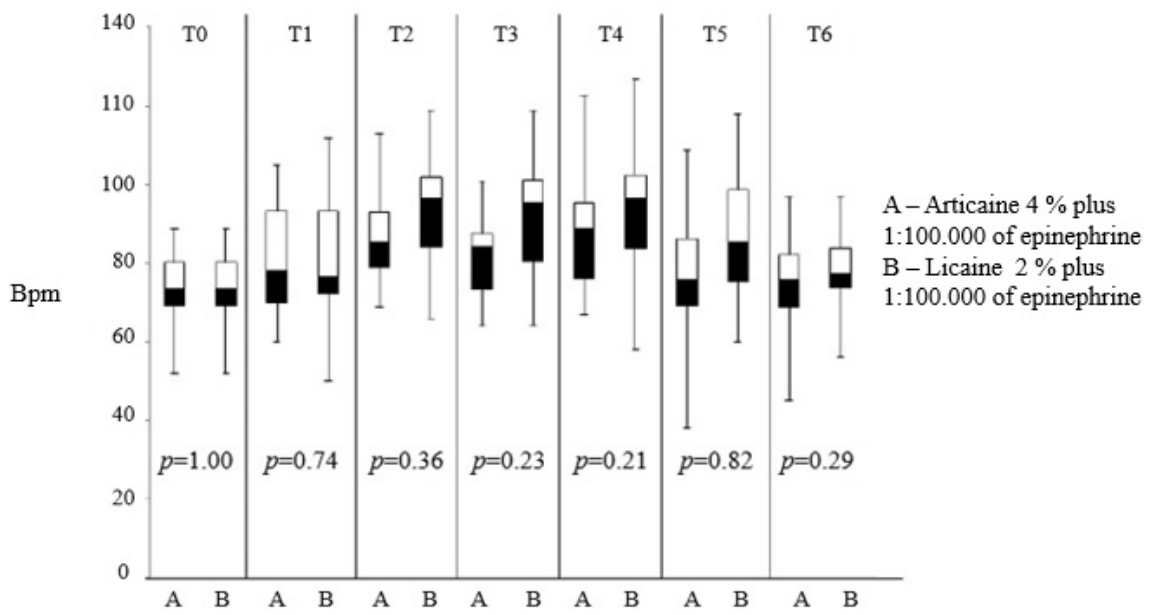

Fig. 5. Heart rate difference in every moment during surgery, comparing articaine and lidocaine; $p<0.05$ : Statistically significant difference.

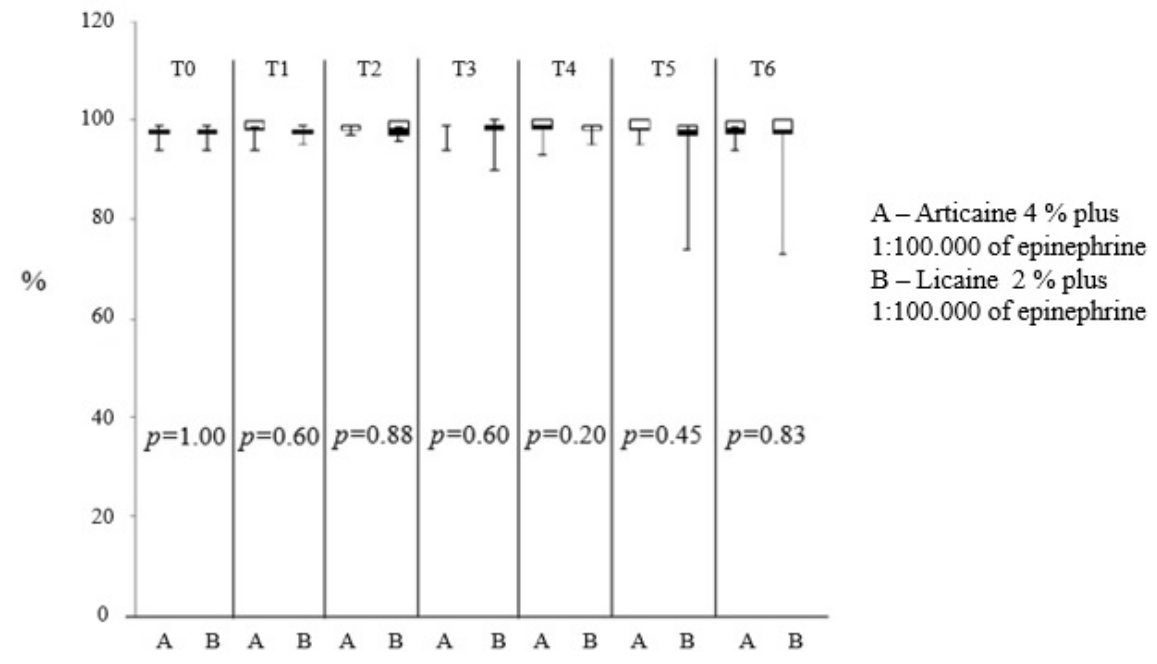

Fig. 6. Oxygen saturation in the blood difference in every moment during surgery, comparing articaine and lidocaine; $p<0.05$ : Statistically significant difference. 
Significant differences were recorded between the SBP, DBP, MAP and HR and between the time points within each group. The following variations were recorded in the articaine group (A): a significant decrease in SBP was recorded between time point T4 and time point T6; there was a significant decrease in DBP at time points T2, T3 and when compared with $\mathrm{T} 1$; there was a significant decrease in the MAP at time points T3 and T5 when compared with T1; a significant increase in $\mathrm{HR}$ was recorded at time points T2 and T4, when compared with T1; a significant decrease in HR was recorded at time point T2, when compared with time point T4 (Table I).

In the lidocaine group, there was a significant difference between the DBP and HR values at different time points during the assessment: a significant decrease of the mean DBP was recorded at time points T2, T3 and $\mathrm{T} 5$, when compared with $\mathrm{T} 1$; an increase in the mean $\mathrm{HR}$ was recorded at time points $\mathrm{T} 2, \mathrm{~T} 3, \mathrm{~T} 4$ and $\mathrm{T} 5$, when compared with $\mathrm{T} 1$; and a significant decrease in the mean HR was recorded at time point T6, when compared with time points $\mathrm{T} 2$ and $\mathrm{T} 4$ (Table I).

Table I. Difference between the moments of hemodynamic evaluation in each group.

\begin{tabular}{|c|c|c|c|c|c|c|c|c|c|c|c|}
\hline \multicolumn{2}{|c|}{$\begin{array}{r}\text { Variable } \\
\text { Articaine }\end{array}$} & \multirow{2}{*}{$\begin{array}{r}N \\
14\end{array}$} & \multirow{2}{*}{$\begin{array}{r}\text { Mean } \\
116.64\end{array}$} & \multirow{2}{*}{$\begin{array}{r}\text { SD } \\
12.84\end{array}$} & \multirow[t]{2}{*}{$p$} & \multicolumn{2}{|c|}{$\begin{array}{l}\text { Variable } \\
\text { Lidocaine }\end{array}$} & \multirow[b]{2}{*}{14} & \multicolumn{2}{|c|}{ Mean } & \multirow[t]{2}{*}{$p$} \\
\hline SBP & (T4) & & & & & SBP & (T4) & & 120.71 & 13.66 & \\
\hline SBP & (T6) & 14 & 111.92 & 12.25 & $0.018^{*}$ & SBP & (T6) & 14 & 113.64 & 11.94 & 0.068 \\
\hline DBP & (T0) & 14 & 71.35 & 6.05 & & DBP & (TO) & 14 & 71.35 & 6.05 & \\
\hline DBP & (T2) & 14 & 59.42 & 10.66 & $0.046^{*}$ & DBP & (T2) & 14 & 61.50 & 8.04 & $0.029^{*}$ \\
\hline DBP & (T0) & 14 & 71.35 & 6.05 & & DBP & (T0) & 14 & 71.35 & 6.05 & \\
\hline DBP & (T3) & 14 & 57.71 & 10.26 & $0.015^{*}$ & DBP & (T3) & 14 & 59.85 & 7.63 & $0.016^{*}$ \\
\hline DBP & (T0) & 14 & 71.35 & 6.05 & & DBP & (T0) & 14 & 71.35 & 6.05 & \\
\hline DBP & (T5) & 14 & 58.50 & 8.22 & $0.004^{*}$ & DBP & (T5) & 14 & 58.14 & 8.64 & $0.008^{*}$ \\
\hline MAP & (T0) & 14 & 86.64 & 5.93 & & MAP & (T0) & 14 & 86.64 & 5.93 & \\
\hline MAP & (T3) & 14 & 76.42 & 10.09 & $0.023^{*}$ & MAP & (T3) & 14 & 79.57 & 8.69 & 0.171 \\
\hline MAP & (T0) & 14 & 86.64 & 5.93 & & MAP & (T0) & 14 & 86.64 & 5.93 & \\
\hline MAP & (T5) & 14 & 76.57 & 9.38 & $0.016^{*}$ & MAP & (T5) & 14 & 77.28 & 9.47 & 0.069 \\
\hline $\mathrm{HR}$ & (T0) & 14 & 74.00 & 9.29 & & $\mathrm{HR}$ & (T0) & 14 & 74.00 & 9.29 & \\
\hline $\mathrm{HR}$ & (T2) & 14 & 87.85 & 11.60 & $0.002^{*}$ & $\mathrm{HR}$ & (T2) & 14 & 94.14 & 15.18 & $0.000^{*}$ \\
\hline $\mathrm{HR}$ & (T0) & 14 & 74.00 & 9.29 & & $\mathrm{HR}$ & (T0) & 14 & 74.00 & 9.29 & \\
\hline HR & (T3) & 14 & 84.85 & 15.79 & 0.133 & $\mathrm{HR}$ & (T3) & 14 & 92.21 & 15.86 & $0.001^{*}$ \\
\hline $\mathrm{HR}$ & (T0) & 14 & 74.00 & 9.29 & & $\mathrm{HR}$ & (T0) & 14 & 74.00 & 9.29 & \\
\hline HR & (T4) & 14 & 87.21 & 15.08 & $0.007^{*}$ & HR & (T4) & 14 & 95.28 & 18.15 & $0.000^{*}$ \\
\hline HR & (TO) & 14 & 74.00 & 9.29 & & HR & (TO) & 14 & 74.00 & 9.29 & \\
\hline HR & (T5) & 14 & 76.64 & 16.38 & 1.000 & $\mathrm{HR}$ & (T5) & 14 & 88.00 & 16.85 & $0.014^{*}$ \\
\hline HR & (T2) & 14 & 87.85 & 11.60 & & HR & (T2) & 14 & 94.14 & 15.18 & \\
\hline HR & (T6) & 14 & 73.92 & 13.26 & $0.003^{*}$ & HR & (T6) & 14 & 79.35 & 13.40 & $0.003^{*}$ \\
\hline HR & (T4) & 14 & 87.21 & 15.08 & & $\mathrm{HR}$ & (T4) & 14 & 95.28 & 18.15 & \\
\hline HR & (T6) & 14 & 73.92 & 13.26 & $0.000^{*}$ & HR & (T6) & 14 & 79.35 & 13.40 & $0.014^{*}$ \\
\hline
\end{tabular}

SDP - Systolic blood pressure, DBP - Diastolic blood pressure, MAP - Mean arterial pressure, HR - Heart rate; T0 - Baseline, T1 - during the injection of the local anesthetic, T2 - two minutes after the injection of the anesthetic, T3 - incision and displacement of the soft tissue, T4 - osteotomy, odontosection and luxation, T5 - cleaning the cavity and suture e T6 - five minutes after the end of the procedure; Repeated measures test; * : Statistically significant difference.

\section{DISCUSSION}

The results of the present study confirmed that there were no significant differences between lidocaine and articaine. However, there were hemodynamic variations between the time points measured within each group. The literature contains studies that assessed variations in hemodynamic behavior at certain moments during the extraction of impacted third molars, usually comparing the effects of two local anesthetics (Vasconcellos et al.; Mestre Aspa et al., 2011; Sancho-Puchades et al.; de Morais et al., 
$2012 a, b)$. The present study compared lidocaine $2 \%$ and articaine $4 \%$, both with epinephrine 1:100.000. Although there was no difference in the comparison between the groups, the present study assessed the hemodynamic behavior at a greater number of time points (during the surgery) than earlier studies. The assessments at seven different time points (T1 - T6) confirmed that variations in hemodynamic behavior could be correlated with the patient's feelings during the procedure and attributed to their stress levels during the surgery, given that the hemodynamic condition was assessed at each stage of the surgery.

A split-mouth design is useful in that it eliminates variations caused by individual differences. The surgical technique and the surgeon should be the same for all procedures, and the patients should be carefully selected to ensure similar trauma during both surgical operations (Lökken et al., 1975). It is also important to highlight that the results of the present study were obtained with identical volumes of both of the anesthetic solutions used $(5.4 \mathrm{ml})$, thereby minimizing any bias, as was the case in earlier studies (Colombini et al., 2006; Santos et al., 2007; Vasconcellos et al.; de Morais et al., 2012a). Even with the quantity of anesthetic limited to $5.4 \mathrm{ml}$, none of the patients complained of trans-operative pain during the surgery. Thus, pain was not the cause of the hemodynamic alterations during the assessments.

It used the device DX 2023 Dixtal multiparametric vital signs monitor, this device is produced for hospital environments and enables the performance of non-invasive assessments of blood pressure, oximetry, electrocardiography, respiration, temperature and arrhythmia analysis. Thus, the use of this apparatus at several time points during the surgical procedure allowed us to perform a more accurate and complete assessment of the variations in the patient's hemodynamic behavior, when compared with the hemodynamic assessments performed in earlier studies (Vasconcellos et al.; Mestre Aspa et al.; Sancho-Puchades et al.; de Morais et al., 2012a,b).

The results of the present study suggest that there were no significant alterations in hemodynamic behavior when comparing the use of the anesthetics lidocaine $2 \%$ and articaine $4 \%$ on healthy patients who were submitted to the extraction of impacted lower third molars. Despite conducting a more thorough assessment than earlier studies (seven time points), the results of this investigation were similar to the vast majority of cases found in the literature, which generally only assessed some of these variables (Oertel et al., 1999; Malamed et al., 2001; Ogunlewe et al., 2011; Silvestre et al.; de Morais et al., 2012a,b). Therefore, the hemodynamic variations in the patients seem to be more closely related to the stress caused by the surgery than the use of a local anesthetic, given that variations were only found between the time points in each of the groups.

In the present study, SBP did not vary significantly between the anesthetics at any of the time points during the procedure. The maximum variation was $5 \mathrm{mmHg}$ at time point T3 (Fig. 1), which is in accordance with earlier studies (Matsumura et al., 1998; Oertel et al., 1999; Malamed et al., 2001; Vasconcellos et al.; de Morais et al., 2012b). Similarly, no statistically significant differences were found for DBP, with a maximum variation of $2 \mathrm{mmHg}$ recorded at time points T2, T3 and T4 (Fig. 2), similar to the MAP (Fig. 3). HR values varied significantly in a number of earlier studies (Salonen et al., 1998; Niwa et al., 2001; Vasconcellos et al.), which was not the case in the present study or in other previous studies (Mestre Aspa et al.; de Morais et al., 2012b), in which no alterations to HR were correlated with the use of anesthetic solutions (Fig. 4). Similar to the other variables, $\mathrm{SaO} 2$ did not exhibit variations at any of the time points assessed (Fig. 5). These differences in the results could be due to the distinct assessment methods used in each study, as well as the condition of the patients during the procedures.

A previous study (de Morais et al., 2012a) assessed the same anesthetics using a vital signs monitor. The authors reported no significant differences for SBP, DBP, HR and oxygen saturation at all of the time points used $(p>0.05)$. Despite the fact that the authors used only four time points during the procedure, the results were the same as those recorded in the present study, which used seven distinct time points, similar to a previous study (Santos et al.). However, the same study (de Morais et al., 2012a) did not confirm the presence of alterations between the time points within each group, unlike the present study. These assessments confirmed significant variations within each group for certain hemodynamic variables during the procedure.

Unlike this investigation, earlier studies confirmed that it is possible to find variations in hemodynamic behavior when comparing local anesthetics (Vasconcellos et al.; Sancho-Puchades 
et al.). Other studies confirmed variations between the different time points assessed during the surgical procedure (Tsuchihashi et al.; Matsumura et al.; Vasconcellos et al.; Sancho-Puchades et al.), similar to the present study. Vasconcellos et al., only used four time points in their investigation, although they found significant variations between a group of patients that received lidocaine $2 \%$ and another that received articaine $4 \%$, both in association with epinephrine (1:100.000). The same authors recorded an increase in DBP and the MAP prior to anesthesia, as well as in the MAP immediately after anesthesia, among patients who received lidocaine $2 \%$, when compared with baseline. The period before anesthesia (first time point) is very tense for patients, as they are expecting a negative experience, which perhaps explains the increases in the MAP and DBP in relation to baseline values. At the second time point, after the anesthesia, the patient still exhibits abnormal values, probably due to the level of anxiety and the injection of the anesthetic.

Table I displays the variations in hemodynamic behavior between the different time points assessed during the surgical procedure in the present study. There was a significant decrease in SBP between T4 and T6 in the articaine group. In the lidocaine group, no significant differences occurred, despite the fact that there was a decrease in the mean SBP values between T4 and T6. This variation may have been due to the fact that the patients relaxed after the procedure had been finished. This result differs from those reported by Vasconcellos et al., who only found a variation in SBP in the articaine group at the "anesthesia" and "post-anesthesia" time points. Tsuchihashi et al. also found different results, recording a significant increase in SBP two minutes after the injection of the anesthetic, when compared with the baseline values. The results of the present study also differ from certain findings reported by Sancho-Puchades et al., who stated that SBP varies significantly over time, increasing gradually from the baseline value until the moment of bone removal. The same authors also reported that SBP decreased between the removal of this bone and the performance of suture among patients anesthetized with articaine $4 \%$. However, this study compared articaine and bupivacaine. In the opinion of the authors of the present study, it is clear that the variation in the SBP of healthy patients submitted to the extraction of lower third molars varies in accordance with the length of the surgery, given that the decrease in the mean SBP value five minutes after the end of the procedure (T6) is statistically less than the T4 value (osteotomy, odontosection and luxation). The length of the procedure causes the greatest feelings of discomfort among patients, together with noises and increased pressure.

Concerning DBP, several alterations occurred during the procedure (Table I). Surprisingly, DBP decreased at a number of time points (T2, T3 and T5) in relation to the baseline values (T0), unlike all previous studies that used this assessment (Tsuchihashi et al.; Matsumura et al.; Vasconcellos et al.; SanchoPuchades et al.). Since the patients selected for the present study did not suffer from any heart conditions, these results could be due to the emotional impact of the surgery, which was most visible at these time points. However, further research is required to substantiate this theory. The MAP also varied between T3 and T5 in relation to T0, although only when articaine $4 \%$ was used, with a decrease in the values. Opposite values were found by Vasconcellos et al., who reported a slight increase in the lidocaine group, and by Tsuchihashi et al., who found no significant differences between the assessments.

There was a great variation between the HR values at the different time points in both groups (Table I). These alterations have also been confirmed in previous studies. Vasconcellos et al., reported that the greatest increase in HR occurred immediately after the anesthesia in both groups (lidocaine and articaine), when the values were compared with baseline, similar to the articaine group in the present study. In the lidocaine group, the highest HR value was found during osteotomy/odontosection/luxation, similar to a study by Matsumura et al., who recorded significant increases after anesthesia and during the removal of the tooth. These results are also similar to those reported in a study by Sancho-Puchades et al., in which the highest $H R$ values among patients anesthetized with articaine were recorded at the time of incision and when the bone tissue was being removed.

According to Matsumura et al., these large variations in the HR may be due to a combination of factors, including painful stimuli, psychological stress and the direct effect of adrenaline on the anesthetic locations, which can lead to this type of sympathetic response. In the present study, an assessment of painful stimuli was not conducted immediately after the surgery, which could represent a limitation of this research. The patient's stress level during the procedure was also not assessed. These results may explain some of the hemodynamic variations. 


\section{CONCLUSION}

There was no variation in the hemodynamic behavior of patients who had lower third molars extracted, when comparing the administration of lidocaine $(2 \%)$ and articaine $4 \%$. Conversely, hemodynamic differences were recorded among the patients when comparing the different time points of the surgical procedure within each of the anesthetic groups assessed.

\section{ACKNOWLEDGMENTS}

The authors thank the Foundation for Research Support of the State of Minas Gerais (FAPEMIG, Minas Gerais, Brazil) and Higher Education Personnel Improvement Coordination (CAPES, Brazil) for the financial support.

STELLA, P. E. M.; FALCI, S. G. M. ; COELHO, V. S. \& DOS SANTOS, C. R. R. Comportamiento hemodinámico en cirugías de los terceros molares utilizando lidocaína vs articaina. Int. J. Odontostomat., 12(1):76-85, 2018.

RESUMEN: El objetivo de esta investigación fue evaluar las variaciones hemodinámicas durante la extracción de terceros molares inferiores impactados utilizando lidocaína al $2 \%$ o articaína al $4 \%$, como anestésicos locales. Catorce pacientes con una edad promedio de 22,4 años $(S D=3,25)$, fueron sometidos a la extracción bilateral de terceros molares inferiores, con un intervalo de tres a cuatro semanas entre las dos extracciones. Se evaluaron la presión arterial sistólica, la presión arterial diastólica, la presión arterial media, la frecuencia cardíaca y la saturación de oxígeno en la sangre, en siete momentos específicos: línea base; punción anestésica; dos minutos después de la anestesia; osteotomía; sutura y cinco minutos después de que el procedimiento fue completado. El análisis estadístico involucró el análisis descriptivo, la prueba de Shapiro-Wilk, la prueba de Mann-Whitney, la prueba t y la prueba de mediciones repetidas. No se encontraron diferencias significativas para ninguna de las variables de comportamiento hemodinámico al comparar lidocaína $2 \%$ y articaína 4 $\%$. Se encontraron diferencias significativas entre los puntos de tiempo evaluados dentro de cada grupo, particularmente en relación con la frecuencia cardíaca variable. En el grupo de articaína, la presión arterial sistólica exhibió una disminución significativa cinco minutos después del procedimiento. No se observaron variaciones significativas en el comportamiento hemodinámico entre los dos grupos anestésicos diferentes (articaína 4 \% y lidocaína $2 \%$ ).

PALABRAS CLAVE: cirugía oral, terceros molares, lidocaína, articaína, presión arterial.

\section{REFERENCES}

Abraham-Inpijn, L.; Borgmeijer-Hoelen, A. \& Gortzak, R. A. Changes in blood pressure, heart rate, and electrocardiogram during dental treatment with use of local anesthesia. J. Am. Dent. Assoc., 116(4):531-6, 1988.

Colombini, B. L.; Modena, K. C.; Calvo, A. M.; Sakai, V. T.; Giglio, F. P.; Dionísio, T. J.; Trindade, A. S. Jr.; Lauris, J. R. \& Santos, C. F. Articaine and mepivacaine efficacy in postoperative analgesia for lower third molar removal: a double-blind, randomized, crossover study. Oral Surg. Oral Med. Oral Pathol. Oral Radiol. Endod., 102(2):169-74, 2006.

Daubländer, M.; Müller, R. \& Lipp, M. D. The incidence of complications associated with local anesthesia in dentistry. Anesth. Prog., 44(4):132-41, 1997.

de Morais, H. H.; de Santana Santos, T.; Araújo, F. A.; Vajgel, A. \& de Holanda Vasconcellos, R. J. Hemodynamic changes comparing lidocaine $\mathrm{HCl}$ with epinephrine and articaine $\mathrm{HCl}$ with epinephrine. J. Craniofac. Surg., 23(6):1703-8, 2012b.

de Morais, H. H.; de Santana Santos, T.; da Costa Araújo, F. A.; de Freitas Xavier, R. L.; Vajgel, A. \& de Holanda Vasconcellos, R. J. Hemodynamic changes comparing $2 \%$ lidocaine and $4 \%$ articaine with epinephrine 1: 100,000 in lower third molar surgery. J. Craniofac. Surg., 23(4):1204-11, $2012 a$.

Elad, S.; Admon, D.; Kedmi, M.; Naveh, E.; Benzki, E.; Ayalon, S.; Tuchband, A.; Lutan, H. \& Kaufman, E. The cardiovascular effect of local anesthesia with articaine plus 1:200,000 adrenalin versus lidocaine plus 1:100,000 adrenalin in medically compromised cardiac patients: a prospective, randomized, double blinded study. Oral Surg. Oral Med. Oral Pathol. Oral Radiol. Endod., 105(6):725-30, 2008.

Gortzak, R. A.; Oosting, J. \& Abraham-Inpijn, L. Blood pressure response to routine restorative dental treatment with and without local anesthesia. Continuous noninvasive blood pressure registration with a finger manometer. Oral Surg. Oral Med. Oral Pathol., 73(6):677-81, 1992.

Kim, K.; Brar, P.; Jakubowski, J.; Kaltman, S. \& Lopez, E. The use of corticosteroids and nonsteroidal antiinflammatory medication for the management of pain and inflammation after third molar surgery: a review of the literature. Oral Surg. Oral Med. Oral Pathol. Oral Radiol. Endod., 107(5):630-40, 2009.

Laragnoit, A. B.; Neves, R. S.; Neves, I. L. \& Vieria, J. E. Locoregional anesthesia for dental treatment in cardiac patients: a comparative study of $2 \%$ plain lidocaine and $2 \%$ lidocaine with epinephrine (1:100,000). Clinics (Sao Paulo), 64(3):177-82, 2009.

Lökken, P.; Olsen, I.; Bruaset, I. \& Norman-Pedersen, K. Bilateral surgical removal of impacted lower third molar teeth as a model for drug evaluation: a test with ibuprofen. Eur. J. Clin. Pharmacol., 8(3-4):209-16, 1975.

Malamed, S. F.; Gagnon, S. \& Leblanc, D. Articaine hydrochloride: a study of the safety of a new amide local anesthetic. J. Am. Dent. Assoc., 132(2):177-85, 2001.

Malamed, S. F.; Gagnon, S. \& Leblanc, D. Efficacy of articaine: a new amide local anesthetic. J. Am. Dent. Assoc., 131(5):63542, 2000.

Matsumura, K.; Miura, K.; Takata, Y.; Kurokawa, H.; Kajiyama, M.; Abe, I. \& Fujishima, M. Changes in blood pressure and heart rate variability during dental surgery. Am. J. Hypertens., 11(11 Pt. 1):1376-80, 1998.

Meiller, T. F.; Overholser, C. D.; Kutcher, M. J. \& Bennett, R. Blood pressure fluctuations in hypertensive patients during oral surgery. J. Oral Maxillofac. Surg., 41(11):715-8, 1993.

Mestre Aspa, R.; Carrera Grañó, I.; Berini Aytés, L. \& Gay Escoda, C. Pulsioxymetry monitorization during lower third molar 
STELLA, P. E. M.; FALCI, S. G. M.; COELHO, V. S. \& DOS SANTOS, C. R. R. Hemodynamic behavior in third molar surgeries using lidocaine or articaine. Int. J. Odontostomat., 12(1):76-85, 2018.

extraction. A comparative study of three local anesthetics with epinephrine 1:100,000. Med. Oral, 6(3):195-204, 2011.

Neves, R. S.; Neves, I. L.; Giorgi, D. M.; Grupi, C. J.; César, L. A.; Hueb, W. \& Grinberg, M. Effects of epinephrine in local dental anesthesia in patients with coronary artery disease. Arq. Bras. Cardiol., 88(5):545-51, 2007.

Niwa, H.; Sugimura, M.; Satoh, Y. \& Tanimoto, A. Cardiovascular response to epinephrine-containing local anesthesia in patients with cardiovascular disease. Oral Surg. Oral Med. Oral Pathol. Oral Radiol. Endod., 92(6):610-6, 2001.

Oertel, R.; Ebert, U.; Rahn, R. \& Kirch, W. The effect of age on pharmacokinetics of the local anesthetic drug articaine. Reg. Anesth. Pain Med., 24(6):524-8, 1999.

Oertel, R.; Oertel, A.; Weile, K.; Gramatté, T. \& Feller, K. The concentration of local anesthetics in the dental alveolus. Comparative studies of lidocaine and articaine in the mandible and maxilla. Schweiz. Monatsschr. Zahnmed., 104(8):952-5, 1994.

Oertel, R.; Rahn, R. \& Kirch, W. Clinical pharmacokinetics of articaine. Clin. Pharmacokinet., 33(6):417-25, 1997.

Ogunlewe, M. O.; James, O.; Ajuluchukwu, J. N.; Ladeinde, A. L.; Adeyemo, W. L. \& Gbotolorun, O. M. Evaluation of haemodynamic changes in hypertensive patients during tooth extraction under local anaesthesia. West Indian Med. J., 60(1):915, 2011.

Pell, G. J. \& Gregory, B. T. Impacted mandibular third molars: classification and modified techniques for removal. Dent. Digest, 39:330-8, 1993.

Salonen, M.; Forssell, H. \& Scheinin, M. Local dental anaesthesia with lidocaine and adrenaline. Effects on plasma catecholamines, heart rate and blood pressure. Int. J. Oral Maxillofac. Surg., 17(6):392-4, 1998.

Sancho-Puchades, M.; Vílchez-Pérez, M. Á.; Valmaseda-Castellón, E.; Paredes-García, J.; Berini-Aytés, L. \& Gay-Escoda, C. Bupivacaine $0.5 \%$ versus articaine $4 \%$ for the removal of lower third molars. A crossover randomized controlled trial. Med. Oral Patol. Oral Cir. Bucal, 17(3):462-8, 2012.

Santos, C. F.; Modena, K. C.; Giglio, F. P.; Sakai, V. T.; Calvo, A. M.; Colombini, B. L.; Sipert, C. R.; Dionísio, T. J.; Faria, F. A.; Trindade, A. S. Jr. \& Lauris, J. R. Epinephrine concentration $(1: 100,000$ or $1: 200,000)$ does not affect the clinical efficacy of $4 \%$ articaine for lower third molar removal: a double-blind, randomized, crossover study. J. Oral Maxillofac. Surg., 65(12):2445-52, 2007.

Schulz, K. F.; Altman, D. G.; Moher, D. \& CONSORT Group. CONSORT 2010 Statement: updated guidelines for reporting parallel group randomised trials. BMJ, 340:c332, 2010.

Silvestre, F. J.; Salvador-Martínez, I.; Bautista, D. \& Silvestre-Rangil, J. Clinical study of hemodynamic changes during extraction in controlled hypertensive patients. Med. Oral Patol. Oral Cir. Bucal, 16(3):e354-8, 2011.

Tolas, A. G.; Pflug, A. E. \& Halter, J. B. Arterial plasma epinephrine concentrations and hemodynamic responses after dental injection of local anesthetic with epinephrine. J. Am. Dent. Assoc., 104(1):41-3, 1982.

Tsuchihashi, T.; Takata, Y.; Kurokawa, H.; Miura, K.; Maruoka, Y.; Kajiyama, M. \& Fujishima, M. Blood pressure response during dental surgery. Hypertens. Res., 19(3):189-94, 1996.

Vasconcellos, R. J.; Vasconcelos, B. C. \& Genú, P. R. Influence of local anesthethics with adrenalina 1:100.000 in basic vital constants during third molar surgery. Med. Oral Patol. Oral Cir. Bucal, 13(7):E431-7, 2008.
Corresponding author:

Prof. Dr. Saulo Gabriel Moreira Falci

Departamento de Odontologia da Faculdade de Ciências Biológicas e da Saúde da Universidade Federal dos Vales do Jequitinhonha e Mucuri

Rua da Glória, 187 - Centro -

Diamantina/MG - CEP 39100-000

BRASIL

Email: saulofalci@hotmail.com

Received: 20-09-2017

Accepted: 23-12-2017 